\title{
The Impact of Two-tier Instruments on Undergraduate Chemistry Teacher Trainees: An Illuminative Assessment
}

\author{
Ruby Hanson \\ University of Education, Winneba, Ghana
}

\begin{abstract}
Research has it that diagnostic tools lead to better teaching and learning strategies as teachers are able to unearth students' deep-seated learning challenges. An illuminative assessment approach was therefore employed to assess how two-tier diagnostic assessments that are alleged to possess inherent capacities to diagnose students' learning difficulties impacted on Ghanaian undergraduate teacher trainees. The obtained results were interpreted within an epistemological framework. Findings indicated that two-tier diagnostic instruments, were effective in revealing learners' conceptual misunderstandings in inorganic chemistry. As many as 43 alternative conceptions were uncovered through the use of diagnostic assessments. These findings would give chemistry teachers an insight into some students' naïve conceptions and add up to existing knowledge about students' learning difficulties as well as how teachers can recognise them.
\end{abstract}

\section{Introduction}

Research into assessing levels of understanding and recognizing conceptions, among students, through emerging simple but effective techniques could provide useful insights into changing roles of teachers and students alike. Many different techniques are used in the measurement of levels of understanding and the identification of naïve conceptions among learners. These techniques could be one or a combination of prediction, observation, concept mapping, interviews, text design, and diagnostic tests. In order to employ such assessment techniques adeptly, teachers must be able to gain conceptual mastery over basic concepts which run through the school curricula. Thus, Ghanaian chemistry teacher trainees with no exception, are expected to acquire such conceptual mastery over basic science concepts that they will teach after their training [1]. Besides, acquisition of content knowledge, they are expected to acquire pedagogical skills [2] that are necessary to help their own students to appreciate chemical principles. In order for teachers to utilise their acquired pedagogical skills to benefit their students, they must endeavour to use diagnostic assessments to find out the entry points of their students so that the best practical teaching skills could be employed [3].
In traditional classrooms, instructors make little or no use of interactive engagement (IE) methods, but rely primarily on passive-student lectures, recipe labs, and algorithmic-problem assessments [4]. Traditional assessments that rely on algorithmic processes fail to unearth the various levels of students' comprehensions in a thorough manner. However, there is evidence that concepts are sometimes structured in students' minds, in ways that are at variance with what a teacher intends, well before they encounter formal school science instruction [5].

In view of the above, many approaches and attempts have been employed by chemistry educators $[6,7,1]$ to find out their students' initial knowledge about some science concepts before they teach them. Teachers' beliefs are that knowing these prior concepts, through the use of diagnostic instruments, would help them to have a suitable, all-encompassing entry point for the introduction of lessons. Some of the diagnostic tools that have been employed by researchers are interviews [8], open-ended responses [9], laboratory activities [3] and multiple-choice tests [10]. Multiple choice tests (MCT) are commonly used in classrooms due to their ease of administration and convenience in scoring. Besides the ease of scoring, MCTs cover a wider scope of assessment of content and provide information about students' content knowledge; more than essays or practical activities would. Nevertheless, the MCTs allow for high chance of guessing wrongly [11], and presents a wrong picture of students' cognitive or conceptual prowess. A diagnostic multiple-choice assessment which is tiered (and demands justification) is therefore a better option for obtaining in-depth knowledge of students' reasoning patterns as it addresses the high percentage of weaknesses in regular MCQ items.

In a two-tier (2-tier) test, each item consists of two multiple choice questions that relate to a problem. The first tier requires a content response while the second tier seeks a reason (justification) for the first response. The second tier of each item could be composed of a set of explanations for answers from the first tier. This second tier is to provide in-depth information about students' understanding and at the same time reveal their alternative conceptions, if any.

Two-tier diagnostic multiple choice tests have been used by Tan, Goh, Chia and Treagust [12], Hanson, Amedeker, Oppong, and Antwi [3], and Hanson $(2017 ; 2018)$, to detect students' conceptions 
in inorganic qualitative analysis, chemical equilibrium, and chemical bonding, respectively. Othman, Treagust and Chandrasegaran [13], also used it in an investigation into the relationship between students' conceptions of the particulate nature of matter (PNM) and their understanding of chemical bonding. Many alternative conceptions were identified in the aforementioned studies. Diagnostic tests on misconceptions, make useful inputs, not only to the body of chemical knowledge by uncovering students' mental structures, but also assist in the process of helping teachers to use such findings to improve their own teaching strategies. Most tier tests are often designed by teachers specifically to identify students' alternative conceptions and knowledge structures, especially in action research, so that the findings are quickly applied for remediation.

Two-tier diagnostic concept tests have been used in various disciplines to diagnose students' problems. Some concepts in chemistry that have been assessed with diagnostic tools are acid base [11], hybridisation [14], water cycle [15] conservation of matter and PNM [16]. Othman et al [13] in the application of the two-tier, found out that students perceived that sodium chloride existed as molecules, while Siswaningsih, Firman, Zackiyah and Khoirunnisa [17], also found that students had misconceptions on the mole concept. Ertugrul and Yilmaz [18] and Haslam et al. [19] used tier tests to enhance students' conceptions about cell division and reproduction, to diagnose their understanding of photosynthesis and respiration in plants as well as to improve students' academic performance on the growth and development of flowering plants. Lin [20] also used tier tests to evaluate students' understanding of flowering plant growth and development. In Physics education, 2-tier and even 4-tier diagnostic tests have been used to assess students' conceptual weaknesses in heat, temperature and static electricity as well as electrical circuits [21]. Chen, Lin and Lin [22] used similar diagnostic tools to enhance the teaching of formation of images by a plane mirror.

\section{Theoretical framework}

From reviewed literature, a number of studies have established that students come to class with diverse unscientific conceptions [21, 12]. However, engaging tiered diagnostic and yet remedial hands-on and minds-on activities have successfully been employed to enable students to deconstruct and reconstruct unscientific chemical phenomena [23]. This study therefore adopted the 2-tier diagnostic tool over a six year period to support active learning and facilitate unearthing of misconceptions and construction of knowledge [24, 22, 21, 12, 20, 25], which has to be evaluated for effectiveness or otherwise The theoretical framework used was program (teaching tool) evaluation or implementation analysis, as proposed by Ryan [26]. The methodology was basically illuminative evaluation [27]. Illuminative evaluation allows researchers to focus on both intentional and unintentional consequences which typically occur in programme implementation $[28,29]$. The illuminative approach involves observation (which was not used in this instance), inquiry, and explanation, with dual focus on instructional systems as well as the learning milieu.

\subsection{Purpose}

This study, sought to evaluate the impact of the 2-tier diagnostic instrument on teacher trainees' conceptual formation and understanding of some selected chemistry concepts in a teaching university, using an adapted Parlett and Hamilton [27] and Yoon, Park and McMillan [29] approach. The main purpose was to review the impact of the 2-tier diagnostic tool which had been in use for close to six years in the University of Education, Winneba, Ghana, and to find out how it had supported active learning by putting implicit emphasis on reflective reasoning to enhance a constructivist model of teaching.

\subsection{Research questions}

1. In what conceptual areas were the 2-tier assessments employed?

2. How effective was the use of the 2-tier assessments in diagnosing students' alternative conceptions in chemistry?

3. What are some of the alternative conceptions in chemistry that were unearthed through the use of the 2-tier test?

4. How did the use of the 2-tier tests address students' alternative conceptions and difficulties in their understanding of chemical principles?

5. How did the diagnostic assessment work among the different year groups?

6. What are the implications for unearthing students' conceptions in chemistry through the tiered diagnostic instrument?

\section{Method}

This was an evaluative document analysis of reports on the use of 2-tier diagnostic tests on different groups of students in various programmes in a Ghanaian institution. A total of 313 chemistry teacher trainees participated in this six-year project at different periods in their four-year studentship tenure at UEW. In some cases, there were double participations. The development of the diagnostic tools for each tier activity followed the three accepted major steps put forth by Treagust [30] for developing tier assessments. The same procedure, as outlined below, was followed by the author in an earlier study They were to: 
i) Identify boundaries of content of study

ii) Obtain information about students' misconceptions through relevant literature that dealt with cognitive structures and conceptual change, in order to develop reason-based items for tier two

iii) Develop a diagnostic assessment with a first tier that requires a content or factual response and a second tier that requires a reason for the factual response.

The 2-tier diagnostic tests that were employed as preand post-assessments to measure change in conceptual understanding in a semester and to assess the credibility of the assessment tool were found to be valid and reliable at their time of administration, with Cronbach alpha values ranging between 0.69 and 0.82 . They also aligned with institutional and departmental curricular goals. Neither factor analysis nor confirmatory factor analysis were required as the class sizes were always small.

Findings were not reviewed against the common regular one-tier diagnostic tests as they were independent of them. The analysis was based solely on obtained documentary evidence from participating students Topics for which the 2-tier assessments covered were acid and base concepts, hybridisation, the particulate nature of matter (PNM), basic chemistry principles (that encompass measurements and periodic properties), and chemical phenomena (like transformations of matter). The different academic years in which such diagnostic studies were carried out are shown in Table 1. Some of the topics were taught in semester 1 (one) only, while others were taught in semester 2 (two) of the designated year. The numbers of trainees who participated are also indicated.

Table 1: Enrolment figures and topic assessed in given year

\begin{tabular}{|l|l|l|l|l|l|l|}
\hline $\begin{array}{l}\text { Roll No. \& study } \\
\text { Period }\end{array}$ & $\begin{array}{c}\mathbf{1 5} \\
(\mathbf{2 0 1 2})\end{array}$ & $\begin{array}{c}\mathbf{2 9} \\
(\mathbf{2 0 1 3})\end{array}$ & $\begin{array}{c}37 \\
(\mathbf{2 0 1 4})\end{array}$ & $\begin{array}{c}\mathbf{5 2} \\
\mathbf{( 2 0 1 5 )}\end{array}$ & $\begin{array}{c}\mathbf{7 8} \\
\mathbf{( 2 0 1 6 )}\end{array}$ & $\begin{array}{c}\mathbf{1 0 2} \\
\mathbf{2 0 1 7}\end{array}$ \\
\hline $\begin{array}{l}\text { Topics } \\
\text { assessed }\end{array}$ & & & & & & \\
\hline $\begin{array}{l}\text { Acid-base } \\
\text { concepts }\end{array}$ & $\sqrt{ }$ & $\times$ & $\sqrt{ }$ & $\sqrt{ }$ & $\times$ & $\sqrt{ }$ \\
\hline Hybridisation & $\sqrt{ }$ & $\times$ & $\sqrt{ }$ & $\sqrt{ }$ & $\times$ & $\times$ \\
\hline $\begin{array}{l}\text { Chemistry } \\
\text { principle }\end{array}$ & $\times$ & $\sqrt{ }$ & $\sqrt{ }$ & $\times$ & $\sqrt{ }$ & $\sqrt{ }$ \\
\hline PNM & $\sqrt{ }$ & $\sqrt{ }$ & $\sqrt{ }$ & $\sqrt{ }$ & $\sqrt{ }$ \\
\hline $\begin{array}{l}\text { Chemical } \\
\text { phenomena }\end{array}$ & $\times$ & $\sqrt{ }$ & $\sqrt{ }$ & $\times$ & $\sqrt{ }$ & $\sqrt{ }$ \\
\hline
\end{tabular}

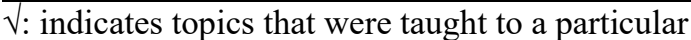
year group using two-tier assessments

$\times$ : a year group within which two-tier documents for specified topics were not employed

\section{Discussion}

Research studies that delve into unveiling students' reasoning patterns enable deeper understanding of content and context issues that need to be emphasised or otherwise by teachers. It is therefore imperative that tools that are employed for such purposes are equally assessed critically. In this vein, a critical review of the 2-tier assessment tool, with its learning milieu and the environment in which the participants in this current research studied, was carried out. Preliminary findings revealed that the teacher trainees, herein referred to as trainees, had faulty cognitive structures about several basic chemical concepts. A few of the identified misconceptions have been presented as Appendix B. It must be noted that some concepts in some of the topics overlap. For example, in the study of chemical principles and chemical phenomena, concepts about acids, hybridisation (in covalent compounds), and PNM were introduced. PNM, as a topic on its own, was however studied in the first semester of each year.

\subsection{PNM}

The particulate nature of matter (PNM) was considered an important concept to research into because previous first year chemistry undergraduates had persistently exhibited many challenges with the required scientific language for discussing changes that occurred among matter. For example, trainees could say that "particles in a solid are more 'compressed' and as such result in a fixed state". The term 'compress' could appropriately be used for gases but not solids; thus, the choice of the scientific word 'compress' was misplaced. In addition, the constant change between the macro and micro particulate level posed a problem to the trainees, as identified also by Treagust et al. [31]. Trainees exhibited cognitive conflicts when they had to use the terms 'atom, ion, and molecule'. They were unable to apply the particulate theory to explain phase changes. The most common alternative concept on PNM was the belief that particles in solids do not move. Similar observations about the immobile nature of solid particles, were made by Boz [32] among six to seventeen-year olds in Turkey.

The trainees' knowledge about the particulate theory were discrete pieces of information even at the tertiary level, possibly because of rote learning at the secondary level. Similar to what Ozmen [33] found out from a 2-tier study in Turkey, trainees in the current study could not imagine nor model the order of spaces between particles, anticipate differentials in movement of particles, or how they would appear in different phases. Banda, Mumba, Chabalengula, and Mbewe [2], used a questionnaire to find out Zambian pre-service teachers' conceptions about PNM, and found that Zambian trainees had non-coordinated conceptions about matter, as was found among trainees in this current study. Earlier studies by Liu and Lesniak [34] indicated that progression of students' conceptions on matter is not automatic from lower to higher education, but a multifaceted progress. This is confirmed by naïve answers that the 
Ghanaian tertiary trainees provided to questions about matter. Similar observations were also obtained in a study conducted by Stojanovska, Soptrajanov and Petrusevski [35] among Macedonian secondary school students, where seven alternative misconceptions about PNM were uncovered diagnostically. This current study however identified only six persistent alternative conceptions among the Ghanaian trainees.

According to Otham et al.'s [13] study, students' poor conceptions of PNM affected their understanding of chemical bonding. This meant that students required the knowledge on how particles were related, with respect to their intermolecular distances spatially, and how they subsequently bonded to other elements with respect to their positions on the periodic table. This effect of poor conceptions about matter and their effects on further understanding of related topics was observed by Hanson $[25,36]$ in Ghana. If learners lack this basic knowledge, then teaching concepts that require the said knowledge as building platforms (sequencing) would be problematic when they have to explain chemical phenomenon in a coherent manner. This reiterates the importance of making in-depth diagnosis through tiered assessments of what one's students know before teaching, so that broken bridges or gaps in knowledge structures would be reconstructed.

\subsection{Acids, bases and salts}

About four categories of alternative conceptions were identified among trainees when the tier tests were employed in 2012, 2014, 2015 and 2017. These were non-scientific, vernacular, non-factual, and conceptual misunderstandings. Pan and Henriques [37] carried out a similar study in California and identified six categories of alternative concepts among students, when they administered multiple choice questions, open-ended questions and interviews for Grade 9 through to undergraduate students. In both the American and Ghanaian studies, learners' knowledge about microscopic properties of acids and bases, acid strength, $\mathrm{pH}$ and hydrolysis of salts were naïve. The Ghanaian trainees' however, showed no problems with macroscopic properties, as Pan and Henriques found in California. The trainees were able to classify the nature of acids correctly. They were more aware of acids than bases, though, and so gave more correct reasoning statements about acids than bases.

Some of the peculiar conceptions that the Ghanaian trainees portrayed were difficulties with conjugate acid-base problems and the properties of indicators. Conjugation in acids and bases were defined without understanding. The implication was that the definitions had been learned by rote and so the trainees failed to assign tangible reasons for chosen 'conjugate' species in their second tier. A similar outcome was observed in a study by Cooper, Kouyoumdjian and Underwood [38]. Centigual and Geban [39] found in their research that students misunderstood the reason for applying indicators as they said that indicators were used to provide neutralisations in titration. Similar observations were made among the Ghanaian trainees.

Furthermore, the trainees in this study exhibited misconceptions about $\mathrm{pH}$, as had been observed by Centigual and Geban [39] and also by Tarhan and Acar-Sesen [40]. The trainees intimated that $\mathrm{pH}$ was always 7 at equivalence point but was neutral at $\mathrm{pH}$ of zero. They also inferred that the higher a $\mathrm{pH}$ value, the higher the acidity of a given solution. As Hanson and Seherri-Jele [23] found in a recent study, where Grade 11 students presumed that if the number of hydrogen atoms in a molecule increased, or was high, then its $\mathrm{pH}$ value decreased, the same was found among the Ghanaian trainees. In other instances, trainees implied that hydrogen ion concentration increased because concentrated acids have high $\mathrm{pH}$ values but dilute acids have low $\mathrm{pH}$ values. They further alleged that diprotic acids were stronger acids than monoprotic acids. With regards to conceptions about salts, the Ghanaian learners intimated that $\mathrm{pH}$ of salts from acid-base reactions were always 7. This was the basis of their wrong interpretations for answers to problems on hydrolysis. One of the biggest alternative conceptions identified among the Ghanaian trainees which was not observed among samples in reviewed literature, was the reliance of these trainees on the Bronsted-Lowry and Arrhenius concepts. They could not identify Lewis acids and bases as their means of such identification were limited to the belief that acids contain hydrogen or hydroxonium ions, while bases contain hydroxide ions. Within the four categories of misconceptions, 13 alternative conceptions were identified. The challenges with the concepts of acids and bases appear to be global.

\subsection{Hybridisation}

Several misconceptions were also identified among the trainees when 2-tier assessments were carried out on hybridisation in 2012, 2014 and 2015. The concept of the 'orbital' was not well understood prior to trainees' study of this topic. Thus, their poor conceptions about the 'orbital' served as hindrance to further understanding about the concept of hybridisation. Trainees perceived orbitals as pathways for electrons. They misunderstood the concept of hybridisation to be 'mixing up of electrons' and not orbitals [14]. They also retained and solved problems with their high school model of atoms, which was insufficient. They believed that species hybridised because they wanted to attain the octet and for the purposes of stability [41]. Due to this vague perception, they explained that hybridisation occurred in ionic species as well; for the purposes of 
attaining stability. In this case, hybridisation was equated with the generalist view about chemical bonding.

In an earlier study by Hanson et al. [14], only $27 \%$ of the trainees in that study stated in their second tier responses that hybridisation was based on the covalent bond principle. A few thought that hybridisation occurred so that electrons would not repulse each other. Others noted that it was to facilitate equal re-distribution of electrons. These erroneous ideas of hybridisation appeared to be popular among the teacher trainees in this study. This could be a carry-over from their secondary schools where the concept of hybridisation is over simplified. In all, as many as 13 misconceptions were uncovered in this current study. Nakiboglu [42], who had carried out a similar study in Turkey, identified 17 misconceptions from $51 \%$ of his study sample. Nakiboglu's study and others point to the fact that the important concept of hybridisation, must be thoroughly diagnosed to assess students' entry points before teaching begins, in order to avoid building further knowledge on misconceptions.

\subsection{Chemical principles and chemical phenomena}

The concepts studied in these topics in 2013, 2014, 2016 and 2017, were similar. Interestingly, similar misconceptions were identified and corrected with the various year groups that participated in the 2-tier studies. Majority of the trainees did not show conceptual understanding of many basic principles such as periodicity, energy transformations in matter, amount of substance, and acid-base properties. Their again displayed uncoordinated reasoning patterns in presenting valid and logical reasons in their second tiers. For example, they were unable to predict and explain with reasons, the products that could result from an acid and a base, or other chemical reactions, though they could think of and sometimes produce a correct product. They could not explain why some salts that were formed from acid-base reactions would hydrolyse to yield acidic or basic solutions, depending on the strengths of the acid or base part of a given salt. They could also not rationalise that acids could be electron acceptors. The trainees had limited conceptions about the chemical characteristics, definitions, and strengths of acids and bases. Their interpretation of buffers was also misconstrued. Neither were these trainees able to understand the nature of solutions. For example, when they had to explain what had happened to a copper salt that had gone into solution, some responded that:

\section{'It is gone'; 'it is no longer there'.}

They could not explain why the resulting solution had turned blue, nor acknowledge that the observable blue colour was a property of particles from the copper sulphate.

These trainees furthermore displayed a few misconceptions about the periodic table. Periodic properties were not well understood and so they were wrongly applied, as identified by other researchers [1]. The trainees were unable to apply known chemical principles from their first tier to explain why group 1 metals reacted more vigorously with water than group 2 metals and many other factual statements that they made. These observations conform with findings from 2-tier studies conducted by Mutlu and Sesen [43] to assess 219 pre-service science teacher undergraduates' understanding of some general chemistry concepts. Mtulu and Sesen identified misconceptions that were as many and akin to what was identified among the Ghanaian teacher trainees. They further recommended the use of tiertests as they have the capacity to unearth many more misconceptions than regular MCQs and enable teachers to understand students' cognitive structures, than other engaging processes. In all, 11 recurring alternative misconceptions were gathered during the period of study.

\section{Conclusion}

The importance of assessing students' prior conceptions in learning has been proved beyond doubt. Literature reviewed in this study reiterated the fact that globally. students at all levels of learning have alternative conceptions about one chemistry concept or the other and so these must necessarily be unearthed for effective teaching and learning [13, 43]. Results from the appraised documents gathered from the 6-year study, using the Parlett and Hamilton [27] evaluative approach, supported by that of Yoon et al. [29] indicate that diagnostic instruments were able to diagnose the extent of learners' understanding better than regular one-tier assessments. It provided useful information related to students' conceptions about the nature of matter, hybridisation, acid-base concepts, and chemical phenomena, that posed challenges for trainees. Evaluated 2-tier diagnostic resources and trainees' products from the study indicated that students perform better when only the first tier (factual content) part of items are considered than when both parts (factual and reasoning) are considered. The trend clearly portrayed that if regular one-tier assessments are administered, students may appear to perform well, though this could only be superficial and not deep-rooted, because sufficient understanding might not have been attained to enable the assignment of logical reasons in a second tier. High scores could be attained by chance, memorisation, or rote learning without appreciable understanding of the underlying reasons.

This study has thus revealed the critical importance of using tier items to probe alternative conceptions at all levels and stages of one's teaching. 
The participants involved in this project became aware of the importance of diagnosing students' preconceptions. This 6-year study of five major topics, using 2-tier diagnostic tools, revealed 43 alternative conceptions- too many for prospective teachers. Finding the underlying reasons or causes of alternative conceptions expose students' faulty reasoning patterns that may require re-aligning for better conceptual understanding. Furthermore, findings from the study also showed that some prior conceptions recurred from one topic to the other; an indication that the gain of permanent learning may not be $100 \%$ with the tier assessments, though it proved to be very useful in revealing alternative conceptions in this study. There is still room for more refinement of diagnostic assessments so that there will be greater certainty that answers which are provided by students in such exercises will be 'true' revelations of their inner thoughts about concepts.

This review paper could provide educators, curricula developers, pre-service and in-service professionals with up-to-date assessment modes. It is, thus, recommended that prior to the teaching of every topic in inorganic chemistry, teachers should endeavour to use various diagnostic tools, especially 2- or more tier assessments to unearth students' irrational and illogical conceptions. It is further suggested that concrete examples, audio-visual aids, videos, and simulations must be used in this digital age to enable learners to form better mental models through visualisation and engaging activities. Collaboration and cooperative learning could also be introduced to enable students to express their innate or learned views.

\section{Implications for teaching and learning}

1. It is worthy to note that this review and its finding are specific for the Ghanaian educational context. It is therefore not appropriate to attempt to generalise these findings to a wider context. However, sufficient description of the context, methodology and data analysis have been provided to enhance transferability and use of the findings.

2. Teachers should teach scientific concepts in a manner that will foster critical thinking rather than use algorithmic principles from memory.

3. Construction-based teaching suggests that since an understanding of students' prior conceptions provide useful insight into their thinking, it should enable teachers to devise diagnostic tools that would reveal students' problems and yet be suitable for remediation. Thus, findings from this study and the diagnostic tools used could raise awareness of how widespread and permanent alternative conceptions are for studies, in their own educational context.

4. Students could be asked to write, draw or describe their thinking prior to instruction and share their naïve ideas. If this is ignored and not done systematically, students will force new knowledge onto incorrect pre-existing models

5. Emphasis must not be placed on how much content students acquire from the content of curriculum but on assessment of, for, and as learning, since tiered assessments help students to express their thinking overtly.

\subsection{Limitation}

This study did not find out the effectiveness of the 2-tier diagnostic tool on a national scale due to time and funding constraints. The instrument was also not administered on the same groups (longitudinally) throughout their tenure of studentship as there was restricted to certain courses in the different semesters that the study was carried out. There were a few content overlaps but not significant enough to draw longitudinal conclusions from the misconceptions uncovered.

\section{References}

[1] R. Hanson, T. A. Kwarteng and V. Antwi, "Undergraduate chemistry teacher trainees' understanding of chemical phenomena," European Journal of Basic and Applied Sciences, vol. 2, no. 3, pp. 8-14, 2015.

[2] A. Banda, F. Mumba, V. Chabalengula and S. Mbewe, "Teachers' understanding of the particulate nature of matter: The case of Zambian pre-service science teachers," Asia-Pacific Forum on Science Learning and Teaching, vol. 12, no. 2, pp. 1-6, 2011

[3] R. Hanson, M. K. Amedeker, E. Oppong and V. Antwi, "Using microchemistry activities to improve preservice teachers' conceptions of some inorganic chemistry topics," International Journal of Educational Administration, vol. 3, no. 1, pp. 19-40, 2011.

[4] R. R. Hake, "Interactive-engagement versus traditional methods: A six-thousand-student survey of mechanics test data for introductory physics course," American Journal of Physics, vol. 66, no. 1, pp. 64-74, 1998.

[5] A. Sam, K. Niebert, R. Hanson and C. Aryeetey, "Fusing scientists' conceptual correspondences to improve teaching of metal complex isomerism in higher education- An educational reconstructive process," International Journal of Academic Research and Reflection, vol. 4, no. 1, pp. 54-64, 2016.

[6] R. Stavy, "Using analogy to overcome misconceptions about conservation of matter," Journal of Science Teaching, vol. 28, pp. 305-313, 1991. 
[7] S. Aydin, N. Aydemir, Y. Boz, A. Centin-Dindar and O. Bektas, "The contribution of constructivist instruction accompanied by concept mapping in enhancing pre-service chemistry teachers' conceptual understanding of chemistry in the laboratory course," Journal of Science and Educational Technology, vol. 18, pp. 518-534, 2009.

[8] B. Costu, "Big bubbles in boiling liquids: students' view," Chemical Education Research and Practice, vol. 9, pp. 219-224, 2008.

[9] J. M. Nyachwaya, A.-R. Mohamed, G. Roehrig, N. B. Wood, A. L. Kern and J. Schneider, "The development of an open-ended drawing tool: An alternative diagnostic tool for assessing students' understanding of the particulate nature of matter," Chemistry Education Research and Practice, vol. 12, pp. 121-132, 2011

[10] D. F. Treagust, A. L. Chandrasegaran, J. Crowley, B. H. Yung, I. P.-A. Cheong and J. Othman, "Evaluating students' understanding of kinetic particle theory concepts relating to the states of matter, changes of state and diffusion: A cross-national study," International Journal of Science and Mathematics Education, vol. 8, pp. 141-164, 2012.

[11] R. Hanson, K. D. Taale and V. Antwi, "Investigating senior high school students' conceptions of introductory chemistry concepts," International Journal of Educational Administration, vol. 3, no. 1, pp. 41-57, 2011.

[12] K. C. D. Tan, N. K. Goh, L. S. Chia and D. F. Treagust, "Development and application of a two-tier multiple choice diagnostic instrument to assess high school students' understanding of inorganic qualitative analysis," Journal of Research in Science Teaching, vol. 39, pp. 283-301, 2002.

[13] J. Othman, D. F. Treagust and A. L. Chandrasegaran, 'between students' conceptions of the particulate nature of matter and their understanding of chemical bonding," International Journal of Science Education, vol. 30, no. 11, pp. 1532-1550, 2008.

[14] R. Hanson, A. Sam and V. Antwi, "Misconceptions of undergraduate chemistry teachers about hybridisation," African Journal of Educational Studies in Mathematics and Science, vol. 10, no. 1, pp. 43-54, 2012.

[15] W. L. Romie, D. L. Schaffer and L. Barrow, "Development and application of a novel Raschbased methodology for evaluating multi-tiered assessment instruments: Validation and utilization of an undergraduate diagnostic test of the water cycle," International Journal of Science Education, vol. 37, no. 16, pp. 2740-2768, 2015.

[16] K. Salta and C. Tzougraki, "Coceptual versus algorithmic problem-solving: focusing on problems dealing with conservation of matter in chemistry,"
Research in Science Education, vol. 41, no. 1, pp. 587-609, 2011.

[17] W. Siswaningsih, H. Firman, A. Zackiyah and A. Khoirunnisa, "Development of two-tier diagnostic test pictorial-based for identifying high school students' misconceptions on the mole concept," Journal of Physics Conference Series, vol. Series $812,2017$.

[18] S. Ertugrul and K. Yilmaz, "Development and application of a two-tier multiple-choice diagnostic test for high school students' understanding of cell division and reproduction," Journal of Biological Education, vol. 46, no. 4, pp. 214-225, 2012.

[19] F. Haslam, "Diagnosing secondary students' misconceptions of photosynthesis and respiration in plants using a two-tier multiple choice instrument," Journal of Biological Education, vol. 1, pp. 1-8, 2010.

[20] S.-W. Lin, "Development and application of a twotier diagnostic test for high school students' understanding of flowering plant growth and development," International Journal of Science and Mathematics Education, vol. 2, pp. 175-199, 2004.

[21] R. Millar and V. Hames, "Using diagnostic assessment to improve students' learning in science: Some preliminary findings from work to develop and test diagnostic tools," in Third Conference of the European Science Education Research Association (ESERA), Thessaloniki, Greece, 2001.

[22] C.-C. Chen, H.-S. Lin and M.-L. Lin, "Developing a two-tier diagnostic instrument to assess high school students' understanding- the formation of images by a plane mirror," Proceedings of the National Science Council, vol. 12, no. 3, pp. 106-121, 2002.

[23] R. Hanson and N. Seherri-Jele, "Using some conceptual change approaches to strengthen grade 11 students' conceptions about acid strength," Journal of Science Education and Research, vol. 4, no. 1, pp. $36-43,2018$

[24] P. Tamir, "Some issues related to the use of justifications to multiple-choice answers," Journal of Biological Education, vol. 23, no. 4, pp. 285-292, 1989.

[25] R. Hanson, "Unearthing conceptions about types of chemical bonding through the use of tiered worksheets- A case study," International Journal for Cross-Disciplinary Subjects in Education, vol. 8, no. 12, pp. 3112-3122, 2017.

[26] N. Ryan, "Rationality and implementation analysis," Journal of Management History, vol. 5, no. 1, pp. 3652, 1999.

[27] M. Parlett and D. Hamilton, "Evaluation asillumination: A new approach to the study of 
innovatory programs," Centre for Research in the Educational Sciences, Scotland, 1972.

[28] L. Alderman, "Illuminative evaluation applied to government policy in higher education," Evaluation Journal of Australia, vol. 15, no. 1, pp. 4-14, 2015.

[29] S. Yoon, M. E. Park and M. McMillan, "An illuminative evaluation: Student experience of flipped learning using online contents," Journal of Problem-Based Learning, vol. 4, no. 1, pp. 47-54, 2017.

[30] D. F. Treagust, "Development and use of diagnostic tests to evaluate students' misconceptions in science," International Journal of Science Education, vol. 10, no. 2, pp. 159-169, 1988.

[31] D. F. Treagust, A. L. Chandrasegaran, A. N. M. Zain, E. T. Ong, M. Karpudewan and L. Halim, "Evaluation of an intervention instructional program to facilitate understanding of basic particle concepts among students enrolled in several levels of study," Chemical Education Research and/Practice, vol. 12, no. 2, pp. 251-261, 2011.

[32] Y. Boz, "Turkish pupils' conceptions of particulate nature of matter," Journal of Science Education and Tehnology, vol. 15, no. 2, pp. 203-213, 2006.

[33] H. Ozmen, "Turkish primary students' conceptions about the particulate nature of matter," International Journal of Environmental and Science Education, vol. 6 , no. 1 , pp. 99-121, 2011.

[34] X. Liu and K. Lesniak, "Progression in childrens' understanding of the matter concept from elementary to high school," Journal of Research in Science Teaching, vol. 43, no. 3, pp. 320-347, 2006.

[35] M. I. Stojanovska, B. T. Soptrajanov and V. M. Petrusevski, "Addressing misconceptions about the particulate nature of matter among secondary school and high school students in the Republic of Macedonia," Creative Education, vol. 3, no. 5, pp. 619-631, 2012.

[36] R. Hanson, "An illuminative evaluation of the impact of two-tier diagnostic instruments on undergraduate chemistry teacher trainees' conceptions," in Canada International Conference on Education (CICE2019), Mississauga, Ontario, 2019.

[37] H. Pan and L. Henriques, "Students' misconceptions on titrations," School Science and Mathematics, vol. 115, pp. 237-244, 2015.

[38] M. M. Cooper, H. Kouyoumdjian and S. M. Underwood, "Investigating students' reasoning about acid-base reactions," Journal of Chemical Education, vol. 93, pp. 1703-1712, 2016.

[39] I. Centingual and O. Geban, "Using conceptual change texts with analogies for misconceptions in acids and bases," Hacettepe University Journal of Education, vol. 41, pp. 112-123, 2011.

[40] L. Tarhan and B. Acar-Sesen, "Problem based learning in acids and bases: Learning achievements and students' beliefs," Journal of Baltic Science Education, vol. 12, no. 5, pp. 565-578, 2013.

[41] R. Hanson, “An investigation into teacher trainees' understanding of chemical stability and its implications," in Proceedings of International Conference on Education (CICE-2018), University of Toronto,, Mississauga, Ontario, Canada, 2018.

[42] C. Nakiboglu, "Instructional misconceptions of Turkish prospective chemistry teachers about atomic orbitals and hybridisation," Chemistry Education: Research and Practice, vol. 4, no. 2, pp. 171-188, 2003.

[43] A. Mutlu and B. A. Sesen, "Development of a twotier diagnostic test to assess undergraduates' understanding of some chemistry concepts," Procedia-Social and Behavioural Sciences, vol. 174, pp. 629-635, 2015.

\section{Appendix A: Review focus questions}

1. What are the needs of diagnostic test studies?

2. What are the aims of studies of students' conceptions through diagnostic tests?

3. What research methods have been used to assess students' misconceptions? Were they reliable? valid?

4. What common alternative conceptions have been identified?

5. What kinds of implications for teaching and learning have been identified in such studies of students through diagnostic studies?

\section{Appendix B: Some identified misconceptions}

\section{Acid-base strength and reactions}

Strong acids corrode faster than weak acids

The quantity of an acid or base determines its strength A concentrated acid or base is one which is strong, while a weak acid or base is one that is dilute

Acids with many replaceable types of hydrogen are stronger than those with only one; therefore, $\mathrm{CH}_{3} \mathrm{COOH}$ must be a stronger acid than $\mathrm{HCl}, \mathrm{HNO}_{3}$ and even $\mathrm{H}_{2} \mathrm{SO}_{4}$.

Strong solutions contain more acid than weak ones. They have more reacting ability because they are strong. The 'molarity' of an acid/base can determine its strength An acid dissociation constant, Ka of $7.2 \times 10^{-11}$ is bigger than one with a value of $3.4 \times 10^{-8}$ (confusion over integers)

Such 'strong' solutions react very fast but weak ones reacts slowly. (Misconception about concentration) Salts formed from neutralisation reactions are neutral and so yield neutral solutions pH $\mathrm{pH}$ wrongly equated to concentration and equating $\mathrm{pH}$ to dissociation constants 


\begin{tabular}{l}
\hline Misunderstanding about relationship between \\
concentration of ions, dissociation constants and pH \\
Misinterpretation of the term 'buffer' \\
\hline Chemical Phenomena/PNM \\
Nature of elements were assumed to be of various sizes \\
and colours but not with respect to composition \\
Reaction of metals with water: they said that some would \\
dissolve (as if they were salts) while others would \\
remain as if they were inert in solutions \\
Reaction of metals with other chemical species such as \\
acids: Metal species in acid solutions would 'corrode'. \\
Inability to detect the progressive parametric trends \\
across the periodic table and below (group trends). For \\
example, the idea of acid strength with respect to metal \\
cations, or size required the understanding of such \\
changes in parameters. \\
\hline Particulate nature of matter (PNM) \\
Some of the wrong assertions were: \\
Definition of atom, element, compound was used \\
interchangeably \\
Differences between elements, compounds and mixtures \\
were not distinct \\
Inability to discriminate between particulate \\
representations of compounds and elements \\
An element was defined as part of an atom or an element \\
is made up of one substance \\
If a substance did not feel hard, with a fixed form, such \\
as powdered sulphur it was not classified as solids. \\
Matter is made up of discrete particles which are in \\
constant motion yet have bonds between them \\
When the temperature of solids increases, the bonds \\
break and particles 'melt' \\
The attractive force makes particles 'clump together' if \\
the force is strong \\
Physical change takes place because the atoms are the \\
same, with no change of state but chemical change is \\
when states are different \\
Chemical change occurs when the arrow is straight \\
forward and not reversible \\
\hline Hybridisation \\
Concept of 'mixing' up of atoms was confused with \\
mixing up of atoms \\
Inability to comprehend the idea that 'empty' orbitals \\
mixing up. "Electrons must be present. How can the \\
orbitals mix up? Where will electrons come from to fill \\
in the hybrid orbital?"'
\end{tabular}

